
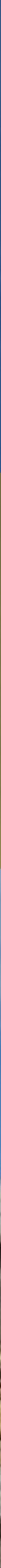


\section{Panta Rei \\ Revista Digital de Ciencia \\ y Didáctica de la Historia}

\section{6}

Revista anual

Fecha de inicio: 1995

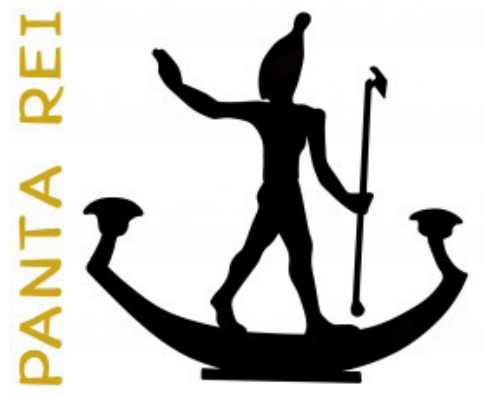

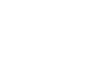




\section{CONSEJO DE REDACCIÓN}

\section{Coordinador editorial}

Egea Vivancos, Alejandro

[Didáctica de las Ciencias Sociales, UMU]

\section{Editores}

Botí Hernández, Juan Jesús

[CEPOAT, UMU]

Meseguer Gil, Antonio José

[CEPOAT, UNED]

Sáez Giménez, David Omar

[CEPOAT, UMU]

Sánchez Mondéjar, Celso Miguel

[CEPOAT, UMU]

\section{Secretaria}

Arias Ferrer, Laura

[Didáctica de las Ciencias Sociales, UMU]

\section{Responsable informático}

Martínez García, José Javier

[CEPOAT, UMU]

\section{Traducción y corrección lingüística}

Martínez Martínez, Cristina

[Sociedad Española de Lenguas Modernas]

Albaladejo Albaladejo, Sara

[ISEN, UMU]

\section{CONSEJO ASESOR}

Albero Muñoz, M. ${ }^{a}$ del Mar

[H. ${ }^{a}$ del Arte, UMU]

Chapman, Arthur

[History Education, UCL, Reino Unido]

Cobacho López, Ángel

[Derecho, UMU]

Egea Bruno, Pedro M. ${ }^{\text {a }}$

[Historia Contemporánea, UMU]

García Atienzar, Gabriel

[Prehistoria, UA]

González Monfort, Neus

[Didáctica de las Ciencias Sociales, UAB]

Haber Uriarte, María

[Prehistoria, UMU]

Hutson, Scott R.

[Anthropology, UK, EEUU]

Irigoyen López, Antonio

[Historia Moderna, UMU]

Mahony, Simon

[Digital Humanities, UCL, Reino Unido]

Marsilla de Pascual, Francisco Reyes

[Técnicas historiográficas, UMU]

Miralles Maldonado, José Carlos

[Filología Clásica, UMU]

Molina Gómez, José Antonio

[Historia Antigua, UMU]

Noguera Celdrán, José Miguel

[Arqueología, UMU]

Pérez Molina, Miguel Emilio

[Filología Clásica, UMU]

Prados Martínez, Fernando

[Arqueología, UA]

Sánchez Ibáñez, Raquel

[Didáctica de las Ciencias Sociales, UMU]

Sancho Gómez, Miguel Pablo

[Educación, UCAM]

Vilar García, María José

[Historia Contemporánea, UMU]

Zamora López, José Ángel

[Próximo Oriente Antiguo, CCHS-CSIC] 

Artículos

Los orígenes de la tecnología a debate: una revisión de las primeras industrias líticas.

Arturo Cueva Temprana.

De arqueología menorquina: Maria Lluïsa Serra Belabre y los círculos talayóticos de Sant Vicenç d' Alcaidús (Alaior, Menorca).

Octavio Torres Gomariz.

Nuevas cuestiones sobre el anfiteatro de Zaragoza.

José David Mendoza Álvarez.

Castidad o castigo. El estupro de las Vestales como símbolo de desorden social en Roma.

Juan Antonio Montalbán Carmona.

La Historia antigua en la Biblioteca de Focio.

Juan Luis Posadas Sánchez.

Usos sociales de la historia. La estrategia de Olga Cossettini, Rosario, 1935-1943.

Paula Caldo, Micaela Pellegrini Malpiedi y Agustina Mosso

Contribuciones a la didáctica de la Historia a través del método de análisis del objeto: como ejemplo... una "vasulla".

Nayra Llonch Molina y Verónica Parisi Moreno.

How are digital methods changing research in the study of the classical world? An EpiDoc case study. Katherine Steiner y Simon Mahony.

\section{Reseñas}

I Congreso Internacional "Creando ciudadanos, construyendo identidades. El uso del patrimonio material e inmaterial en la enseñanza de la historia."

José Díaz Serrano, Ainoa Escribano Miralles, Ana Isabel Ponce Gea y David Verdú González 151

Beckert, S. (2014). Empire of cotton: A global history. New York: Alfred A Knopf. 640 págs.

Ricky D. Mullins Jr..

Coumert, M. y Dumézil, B. (2013): Los reinos bárbaros en Occidente (traducción de Peinado Santaella, R. G.: Les royaumes barbares en Occident, Presses Universitaires de France, 2010). Editorial Universidad de Granada. Granada. 156 págs.

José Ángel Castillo Lozano.

La prehistoria en Las tres edades de Buster Keaton.

Alberto Lombo Montañés y Esther Rodríguez Ortiz.

Normas de publicación/Publishing rules 



\title{
De arqueología menorquina: Maria Lluïsa Serra Belabre y los círculos talayóticos de Sant Vicenç d'Alcaidús (Alaior, Menorca) ${ }^{1}$
}

\author{
Menorcan archaeology: Maria Lluïsa Serra Belabre, the talayotic circles \\ and Sant Vicenç d'Alcaidús (Alaior, Minorca)
}

\begin{abstract}
Octavio Torres Gomariz ${ }^{2}$
Universidad de Alicante
\end{abstract}

Recibido: $14 / 06 / 2016$

Aceptado: 01/09/2016

Para citar este artículo: Torres Gomariz, O. (2016). De arqueología menorquina: Maria Luïsa Serra Belabre y los círculos talayóticos de Sant Vicenç d'Alcaidús (Alaior, Menorca). Panta Rei. Revista Digital de Ciencia y Didáctica de la Historia, 19-36.

ISSNe: 2386-8864

DOI: $10.6018 /$ pantarei/2016/2

\begin{abstract}
Resumen
Maria Lluïsa Serra Belabre (1911 - 1967) fue una arqueóloga menorquina que dedicó su vida al patrimonio cultural de la isla que la vio nacer. Directora de la Casa de Cultura de Maó (Menorca), entre otros muchos cargos que desempeñó, estudió incansable la historia de Menorca a través de sus archivos, bibliotecas y yacimientos arqueológicos. En este trabajo se abordará únicamente su labor investigadora en el campo de la arqueología balear, especialmente en su análisis de las formas arquitectónicas de las comunidades insulares prehistóricas, a través de sus trabajos publicados en múltiples congresos y revistas. De entre todos los yacimientos en los que intervino para su estudio, destaca indudablemente Sant Vicenç d'Alcaidús (Alaior, Menorca), clave interpretativa para sus teorías sobre las viviendas talayóticas.
\end{abstract}

\section{Palabras clave}

Arqueología, historiografía, arquitectura, investigación en ciencias sociales, historia de Europa.

\begin{abstract}
Maria Lluïsa Serra Belabre $(1911$ - 1967) was a Minorcan archaeologist who devoted her life to the cultural heritage of the island where she was born. Director of the Cultural Centre of Mahon (Minorca), among many other positions she held, she studied the history of Menorca tirelessly through their archives, libraries and archaeological sites. In this paper, her research will be addressed only in the field of Archaeology of Balearic Islands, especially in its analysis of the architectural forms of prehistoric island communities, through their numerous conferences and papers published in journals. Of all the sites in which she intervened, he highlights Sant Vicenç d'Alcaidús (Alaior,
\end{abstract}

1 Este trabajo se desarrolla en el marco del Proyecto Modular. Arquitectura fenicio-púnica de la Universidad de Alicante dirigido por F. Prados Martínez. Asimismo, y se ha escrito durante el disfrute de una Beca de Formación en Museología y Museografía en el Museo Arqueológico de Alicante (MARQ). Finalmente, me gustaría agradecer la excepcional ayuda recibida por parte de Joan C. de Nicolás i Mascaró y Helena Jiménez Vialás para la realización de este artículo.

2 Para contactar con el autor: Octavio Torres Gomariz. Universidad de Alicante. Alicante. otg2@alu.ua.es. 
Minorca), stands out as the interpretive key to her theories on Talayotic houses.

\section{Keywords}

Archaeology, Historiography, Architecture, Social sciences research, European history.

\section{M. ${ }^{a}$ Lluïsa Serra Belabre, menorquina ilustre}

La figura y obra de M. ${ }^{a}$ Lluïsa Serra Belabre (Maó, 1911 - 1967) (Figura 1) son indispensables para comprender hoy la historia de Menorca. Fue indudablemente una mujer excepcional. Nunca abandonó la defensa e impulso constante del patrimonio cultural de la isla, superando todo tipo de adversidades en pos de sus principales objetivos: ubicar la isla en el mapa de los estudios históricos nacionales e internacionales, y poner en valor su patrimonio cultural para el beneficio de toda la sociedad menorquina. Ello además en una situación cuando menos convulsa, la España de la dictadura franquista, y en una sociedad acorde con aquellos tiempos, contexto que hace aún más loable la labor de M. ${ }^{a}$ Lluïsa. Ingresó como alumna libre en la Universidad de Barcelona donde adquirió los cimientos de su formación académica, conociendo a diversos profesores que protagonizaban el panorama historiográfico del momento y con los que posteriormente colaboraría en proyectos de investigación, como fue especialmente el caso del catedrático Lluís Pericot. Una vez licenciada emprendió un largo camino jalonado por investigaciones de toda índole, organización de actividades culturales en Menorca, excavaciones arqueológicas en prácticamente todos los yacimientos conocidos de la isla y participación en numerosos congresos científicos. Actividad frenética en definitiva que sólo cesó con su temprana muerte a los 56 años.

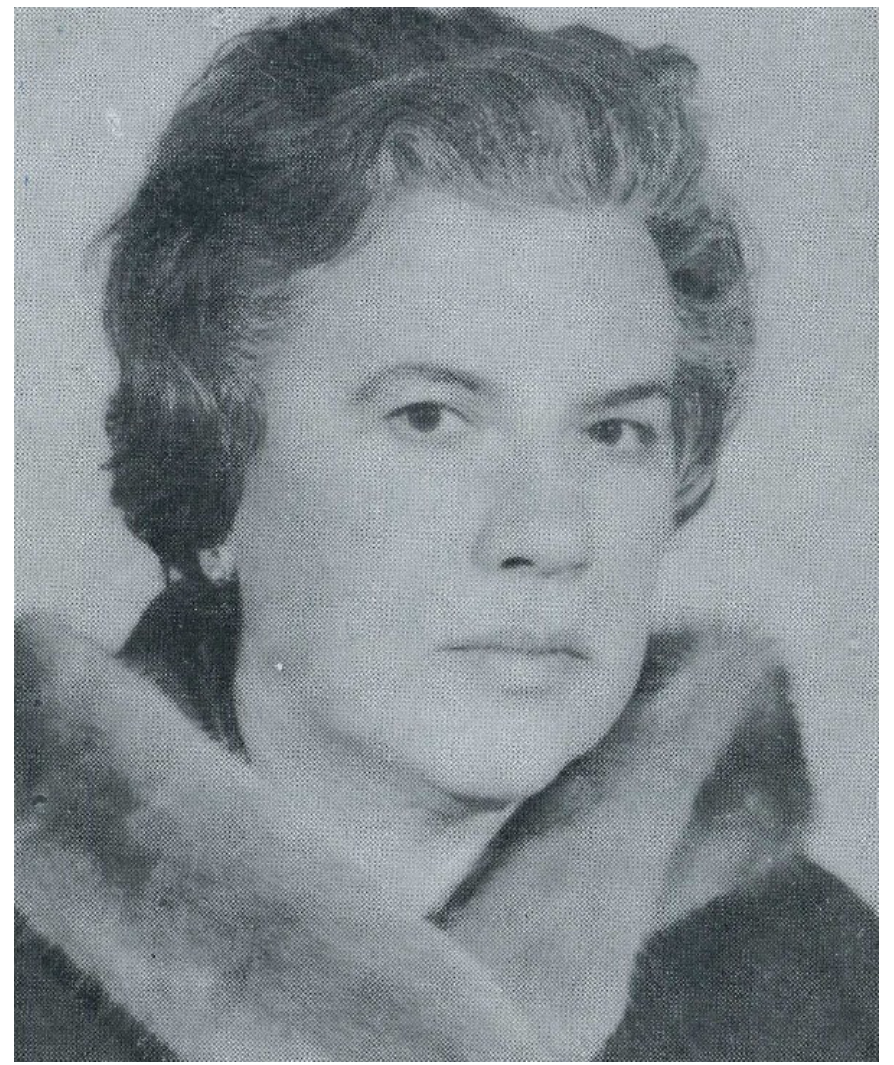

Figura 1: Retrato de M. ${ }^{a}$ Lluïsa Serra Belabre incluido en la contraportada de la Historia de Menorca (1977) Fuente: Serra et al., 1977 
Su vocación y profesionalidad en el desempeño de su labor no pasaron desapercibidas para las instituciones políticas y sociales de su entorno. En 1951 fue nombrada directora interina del Palacio de Archivos, Bibliotecas y Museos de Menorca (posteriormente denominado Casa de Cultura), pasando a dirigir el Museo Provincial de Bellas Artes en 1953, así como la Biblioteca Pública y el Archivo Histórico de Mahón en 1954. Éstas son sólo algunas de las responsabilidades que ejerció, las más representativas, pues fueron también muchas otras, relacionadas íntimamente con la gestión del patrimonio cultural de la isla incluso a niveles estatales, siendo el caso de su nombramiento como Delegada Insular del Servicio Nacional de Excavaciones en 1963.

Su investigación fue tan amplia como abarca el propio concepto de Cultura. Un vistazo a su dilatada bibliografía, compuesta por un centenar de monografías, artículos, actas de congreso y recortes de prensa, ilustra a la perfección su enorme vocación por las Humanidades y las Artes. Ésta incluye desde las particularidades de la geografía física menorquina hasta los protocolos de trabajo propios de la biblioteconomía, pasando por todo tipo de análisis y debates sobre temas locales (gastronomía, vestuario popular, festejos). Sin embargo, si hubo una temática a la que consagró mayores esfuerzos fue sin duda a la historia y la arqueología. Orfila (2012), quien ha dedicado una parte de su investigación a la arqueóloga menorquina, ha apuntado al respecto que estas dos líneas de investigación fueron auspiciadas por dos de sus tutores universitarios: Vicenç Vives y Lluís Pericot. Gran parte de su obra la dedicó a analizar la situación política y económica de la isla en época medieval y moderna, tratando los repartos de tierra tras la Conquista catalano-aragonesa (Serra, 1967a) o también el impacto de las guerras que azotaron el Mediterráneo occidental en el archipiélago balear (Serra, 1967b). Por otra parte, prestó especial atención a recuperar la historiografía propiamente insular, con la compilación de textos no publicados (Serra, 1962a) o el análisis biográfico de diversos personajes ilustres de la isla (por ejemplo, Serra, 1963, entre otros).

No obstante, protagonista indiscutible de su bibliografía es la disciplina arqueológica. Pionera en arqueología medieval, descubrió y excavó las basílicas paleocristianas de Es Fornàs de Torelló y Es Molinet des Cap des Port en Fornells (Serra, 1959), destacando también sus hallazgos en l'Illa del Rei (Serra, 1967c). Sus intervenciones en la naveta des Tudons para su restauración y consolidación en el marco de la Ayuda March, así como las efectuadas en las navetas de Rafal Rubí (Serra, 1961a), supusieron la puesta en valor de ambos yacimientos para asegurar su perduración y legado a la sociedad menorquina. A raíz del proyecto de investigación dirigido por Lluís Pericot emprendió la excavación de múltiples asentamientos prehistóricos de la isla, como son Talatí de Dalt, Son Catlar, San Agustí, Torre d'en Galmés o, de forma exhaustiva, Sant Vicenç d'Alcaidús, al que consagró gran parte de su investigación.

Toda esta labor puede rastrearse con un golpe de vista a su dilatada bibliografía, meritoria más si cabe teniendo en cuenta el corto tiempo de publicación, iniciado tras su licenciatura y extendido hasta su temprano fallecimiento. Por todo ello, abarcar la obra publicada de M. ${ }^{a}$ Lluïsa Serra excede con creces el propósito de este artículo, en el que analizaremos únicamente sus esfuerzos por caracterizar la arquitectura prehistórica de la isla, donde destaca de forma más específica, su labor investigadora desarrollada en torno a los denominados círculos talayóticos, término ya existente pero que fue acuñado definitivamente por la historiografía a raíz de sus importantes trabajos.

\section{El grupo de investigación Estudio de la Edad del Bronce en las Islas Baleares y las primeras intervenciones en Sant Vicenç d'Alcaidús (1958 - 1959)}

Muy próxima a la división entre los términos municipales de Alaior y Maó, se encuentra Sant Vicenç d'Alcaidús (Alaior, Menorca), a escasos 200 metros al norte por el denominado camino de Alcaidusset, desde la actual carretera general (a la altura del $\mathrm{km} \mathrm{6)}$ que une la capital de la isla con Ciutadella, la otra gran urbe insular. El yacimiento era conocido desde hacía tiempo por aquel entonces (años 50-60 del siglo XX), pero apenas frecuentado, por lo que la vegetación lo cubría por completo, dejando a la vista tan sólo algunas pilastras enhiestas (Serra, 1961c). Como la propia M. ${ }^{a}$ Lluïsa relata al inicio de diversos trabajos (Serra, 1966b), el arranque de las intervenciones en 
Alcaidús estuvo auspiciado por el notable interés que manifestó desde su primera visita el Dr. Lluís Pericot, antiguo profesor de M. ${ }^{a}$ Lluïsa en la Universidad de Barcelona y recientemente electo en aquellos años Delegado de Zona de Cataluña y Baleares para asuntos arqueológicos.

El contacto académico recíproco y el interés manifestado por ambos se materializó en la propuesta de Pericot para la creación de un grupo de trabajo que estudiase los yacimientos prehistóricos de la isla. Ésta cristalizó en el llamado proyecto Estudio de la Edad del Bronce en las Islas Baleares, dirigido por él mismo y en el que se encontraba M. ${ }^{a}$ Lluïsa Serra, así como la investigadora María Petrus de Tolós, grandes amigas y compañeras de trabajo (Petrus, 1968). El proyecto sirvió de base para solicitar la ayuda de estudios que ofertaba la Fundación March, obteniéndola en 1958, con un período de dos años de duración, y otorgando al grupo el soporte económico necesario que serviría para arrancar su investigación en Menorca.

Con la concesión de la denominada Ayuda March, el equipo designado bajo la dirección de Pericot inició un amplio programa de excavaciones arqueológicas, estudio de materiales y dibujo de planimetrías de numerosos yacimientos menorquines, con el objetivo de caracterizar las estructuras arquitectónicas de la sociedad talayótica y su cultura material mueble. Fue Sant Vicenç d'Alcaidús el primer objetivo de la investigación. Tras su anterior visita, M. ${ }^{a}$ Lluïsa convenció a Pericot de la potencialidad que ofrecía aquel yacimiento. Durante un primer reconocimiento, muy parcial debido a la gran cantidad de vegetación, pudieron identificar una gran estructura circular con seis pilastras aún in situ (Serra, 1961b); el cierre del poblado por su vertiente septentrional, desapareciendo ante la difícil orografía en dirección noreste; así como la detección de algunas remodelaciones posteriores patentes en la presencia de muros de piedra seca (Serra, 1961c), muy recurrentes y característicos del archipiélago.

La primera medida después de un primer reconocimiento fue el desbroce exhaustivo del lugar. La limpieza consistió en la tala completa de acebuches y demás matorrales que crecían sobre las insinuadas estructuras (Serra, 1961b; 1961c; 1962b). Con la ejecución de estas labores, la visión de Sant Vicenç d'Alcaidús cambió radicalmente. Emergió de entre el espeso matorral una sala hipóstila adosada al muro perimetral de la estructura circular por su vertiente suroeste, mientras que al noreste se identificaron otras cuatro pilastras derruidas, algunos silos, y otras muchas lajas de grandes dimensiones, unas caídas y otras halladas in situ, así como restos de construcciones indeterminadas (Serra, 1961b). Además, se hallaron en el acantilado oriental una serie de cuevas (1961c), comunicadas entre sí, con una finalidad ignorada en un primer momento.

Mientras estas tareas se llevaban a cabo, parte del equipo se trasladó temporalmente al poblado de Torelló (Maó), en julio de 1958, para acometer la excavación de un recinto que, a priori, parecía de taula (Serra, 1961b). Éste quedaba a escasos metros del gran talayot central, uno de los mejores conservados de la isla, y se encontraba dentro de una finca privada. Al igual que en Alcaidús, se desbrozó primero el terreno objeto de intervención, lleno de acebuches y maleza, descubriendo una gran acumulación de piedras de origen probablemente antrópico (Serra, 1961b, 69), entre la que ya se adivinaba los trazos de una gran estructura. Fueron apareciendo entonces restos de muros, compuestos por lajas de gran tamaño sobre bases escuadradas por su parte exterior, mientras que el paramento interior era de piedra pequeña mampuesta con pilastras insertas cada dos metros (1961a), un rasgo este último ya detectado en otros yacimientos, como indica la propia M. ${ }^{a}$ Lluïsa, que interpreta como refuerzo estructural y probable indicador cronológico (Serra, 1961b, n.10). Una vez finalizada completamente la limpieza y extracción de piedra, dichos muros concretaron, al menos superficialmente, un recinto circular de gran tamaño, interrumpido al sur por su destrucción, en cuyo centro se hallaron lajas y pilastras caídas con sus respectivas bases in situ, componiendo un segundo círculo interior; mientras que en la zona occidental quedaron delimitadas tres pequeñas estancias (Serra, 1961a).

Comenzó entonces la excavación de la estructura, dirigida por M. ${ }^{a}$ Lluïsa y María Petrus, cuya primera hipótesis, la del recinto de taula, quedó descartada tras retirar los primeros estratos vegetales. La excavación reveló la presencia de gran cantidad de molinos de mano (amolons) y abundante cerámica local e importada, así como diversas piedras esféricas de pequeño tamaño 
interpretadas como proyectiles de honda, y una ingente cantidad de gasterópodos, acumulados en las áreas sur y central del recinto (Serra, 1961a). Las intervenciones en la parte interior revelaron la técnica de construcción de los muros perimetrales, pero la distribución de las estructuras no encajaba con la propia del recinto de taula, cuyo elemento principal e identificativo era el principal ausente, es decir, en palabras de M. ${ }^{a}$ Lluïsa (1961a), "era un recinto de taula sin taula". Se trataba de una estructura circular con tres espacios internos y con seis pilastras (compuestas por fuste y base cúbica) ubicadas en el centro, constituyendo un patio interior (Serra, 1961b). Sin embargo, su función era una incógnita. Por otra parte, cabe destacar el hallazgo de un tesorillo compuesto por 384 ases romanos republicanos, cubiertos con un fragmento de ánfora romana, datados en torno al siglo I a. C. (Serra, 1961a), que permitieron a M. ${ }^{a}$ Lluïsa, más allá del importante valor que implicaban las monedas, confirmar la reocupación romana del poblado de Torelló.

La dificultad de excavar el centro de la estructura por la caída de las pilastras centrales conllevó la finalización de la excavación del recinto de Torelló en las postrimerías del verano de 1958. Sin embargo, el 29 de septiembre del mismo año se iniciaron los trabajos de excavación del denominado a posteriori Círculo 1 (Serra, 1961b) de Sant Vicenç d'Alcaidús, tras retirar finalmente la vegetación del área circundante, labor que llevaba meses ejecutándose. De nuevo bajo la dirección de M. ${ }^{a}$ Lluïsa Serra y con la compañía de María Petrus (Serra, 1961c), comenzó una excavación marcada en primer lugar, como en Torelló, por la abundante cantidad de piedra acumulada. Al contrario que en el caso anterior, decidieron acotar la intervención a la zona central de la estructura circular, enmarcada por siete pilastras, algunas aún enhiestas. Tras retirar los abundantes niveles de derrumbe, empezó a vislumbrarse un espacio absidal entre dos de las pilastras septentrionales, apareciendo al mismo tiempo gran cantidad de cerámica talayótica, púnica y romana (Serra, 1961c).

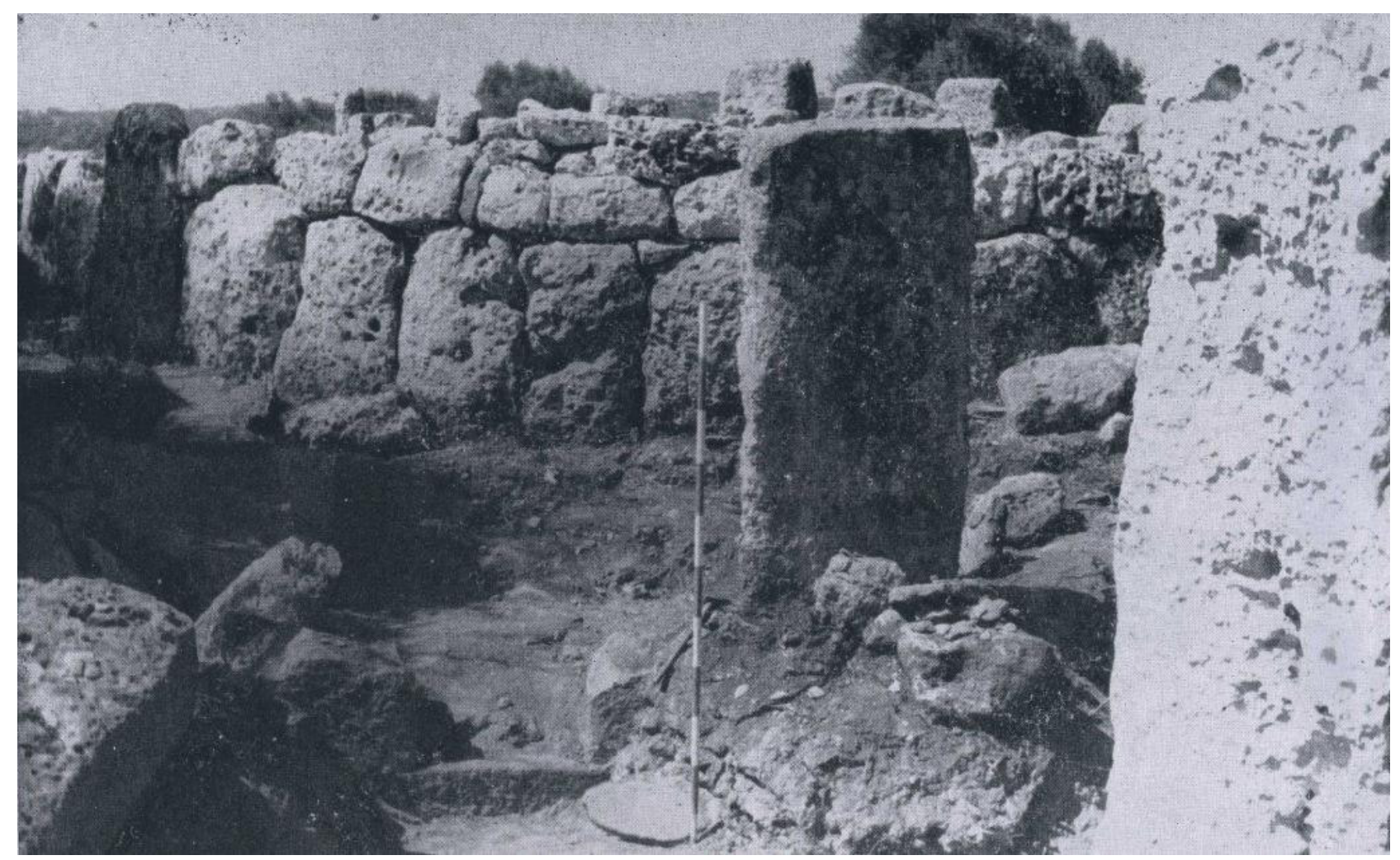

Figura 2: Fotografía de Sant Vicenç d'Alcaidús. En primer término, el Círculo 1; al fondo, el muro perimetral del Círculo 2. Fuente: Serra, 1964a, fig. 2.

La excavación entre la zona de las pilastras y el muro externo del recinto, con el objetivo de entender el funcionamiento arquitectónico y espacial de las estructuras aparecidas, dio como 
resultado la documentación de muros radiales que unían las pilastras centrales entre sí, el ábside y también el paramento interior perimetral (Serra, 1961a, 958), compartimentando el espacio interior y reforzando la hipótesis de una elipse central. El muro perimetral guardaba cierta relación con el observado en Torelló, pues se constituía de grandes lajas de piedra por el exterior, y mampostería con relleno de pequeñas piedra al interior, jalonado además por pilastras verticales insertas en el paño (Serra, 1961c) (Figura 2). La excavación se prolongó cerca de medio metro en profundidad, cuya estratigrafía fue leída e interpretada por M. ${ }^{a}$ Lluïsa, que individualizó dos grandes capas sedimentarias (Serra, 1958-1966 citado en Pons, 2015), hasta topar con unas losas (Serra, 1961a, 1961b) pertenecientes a un pavimento que atribuyó a una ocupación romana del yacimiento. A esta fase se adscribe también un enterramiento ubicado junto a la pilastra sureste, a poca profundidad de la superficie, y datado en torno al siglo II d.C por un disco de lucerna romana (Serra, 1961c).

En cuanto a los materiales muebles, concentrados principalmente en el sector septentrional del recinto, la cerámica es más abundante que el resto, preferentemente talayótica, pero también de origen púnico y romano, destacando especialmente la gran cantidad de ánforas (Serra, 19581966 citado en Pons, 2015); así como dos bordes de kalathos ibéricos (uno de ellos decorado); y finalmente algunos molinos de mano, enteros y fragmentados (Serra, 1961a; 1961c). Es preciso apuntar que durante la intervención se reconstruyó el paramento interior mediante la reversión aproximada del recorrido de caída que habían sufrido los bloques (Serra, 1961b). Con todo ello, a mediados de octubre del año 1958 se dio por finalizada la excavación, debido en parte a la aparición del citado pavimento, pero especialmente por la problemática inherente a la excavación en mayor profundidad de la estructura, con las pilastras completamente exentas (Serra, 1961b) sin consolidar ni asegurar previamente, lo que hizo dudar a M. ${ }^{a}$ Lluïsa de la pertinencia en la continuidad de los trabajos. Finalmente no se retomaría el trabajo en el Círculo 1, por lo que actualmente resta por excavar gran parte de la potencia arqueológica (Pons, 2015), salvo la fase romana.

Un año después, durante el verano de 1959, las tareas previstas por el programa de la Ayuda March requerían pausar las excavaciones y centrarse en la elaboración de planimetrías de los yacimientos menorquines. Para estos trabajos, el equipo dirigido por Pericot recurrió a la incorporación de un topógrafo, Víctor Tolós, que acompañó al grupo a lo largo de la campaña de dibujo (Serra, 1961a). Las dificultades observadas para la excavación de los recintos de Torelló y Alcaidús pueden extrapolarse a la elaboración de planos y dibujos: la abundante vegetación y las ingentes acumulaciones de piedra dificultaron enormemente dicho proceso. La primera parada fue Sant Vicenç d'Alcaidús, cuyo principal objetivo de aquel año era la observación y estudio de la disposición de sus elementos estructurales y los de su entorno inmediato. De esta forma, con las prospecciones exhaustivas y el dibujo planimétrico del terreno, M. ${ }^{a}$ Lluïsa descubrió que el poblado estaba compuesto por un amplio conjunto de círculos secantes entre sí, unos en peor estado de conservación que otros, donde el círculo excavado anteriormente había conservado todo su perímetro, mientras que el resto se adosaban por el lado oriental (Serra, 1961b) aprovechando la estructura lateral para amortizar parte de sus respectivos muros perimetrales (Figura 3).

Con esta hipótesis en mente, el equipo emprendió la confección de los planos de otros yacimientos como Son Catlar (Ciutadella), Talatí de Dalt (Maó) o Torre d'en Galmés (Alaior). En todos ellos descubrieron que el patrón, aunque con algunos matices, se repetía constantemente en todos ellos (Serra, 1961b), siendo la estructura circular de Alcaidús, por ende, un ejemplo más de este tipo, aunque notablemente mejor conservado que el resto (Serra, 1961a). Con el estudio de estos poblados también halló respuesta a otros interrogantes previamente planteados. Por ejemplo, la aparición de las salas hipóstilas adosadas por el lateral de los círculos, como en Alcaidús, también la constató en Torre d'en Galmés; o la cubierta de los recintos, que podría ser como las que se observan en los recintos de Talatí de Dalt, mediante grandes lajas y columnas centrales; o también las dudas sobre la extensión real de los poblados prehistóricos menorquines, como observó en los desconocidos círculos detectados en las inmediaciones de Talatí de Dalt y las múltiples estructuras que quedaron extramuros en Son Catlar con la construcción de la muralla (Serra, 1961a). 


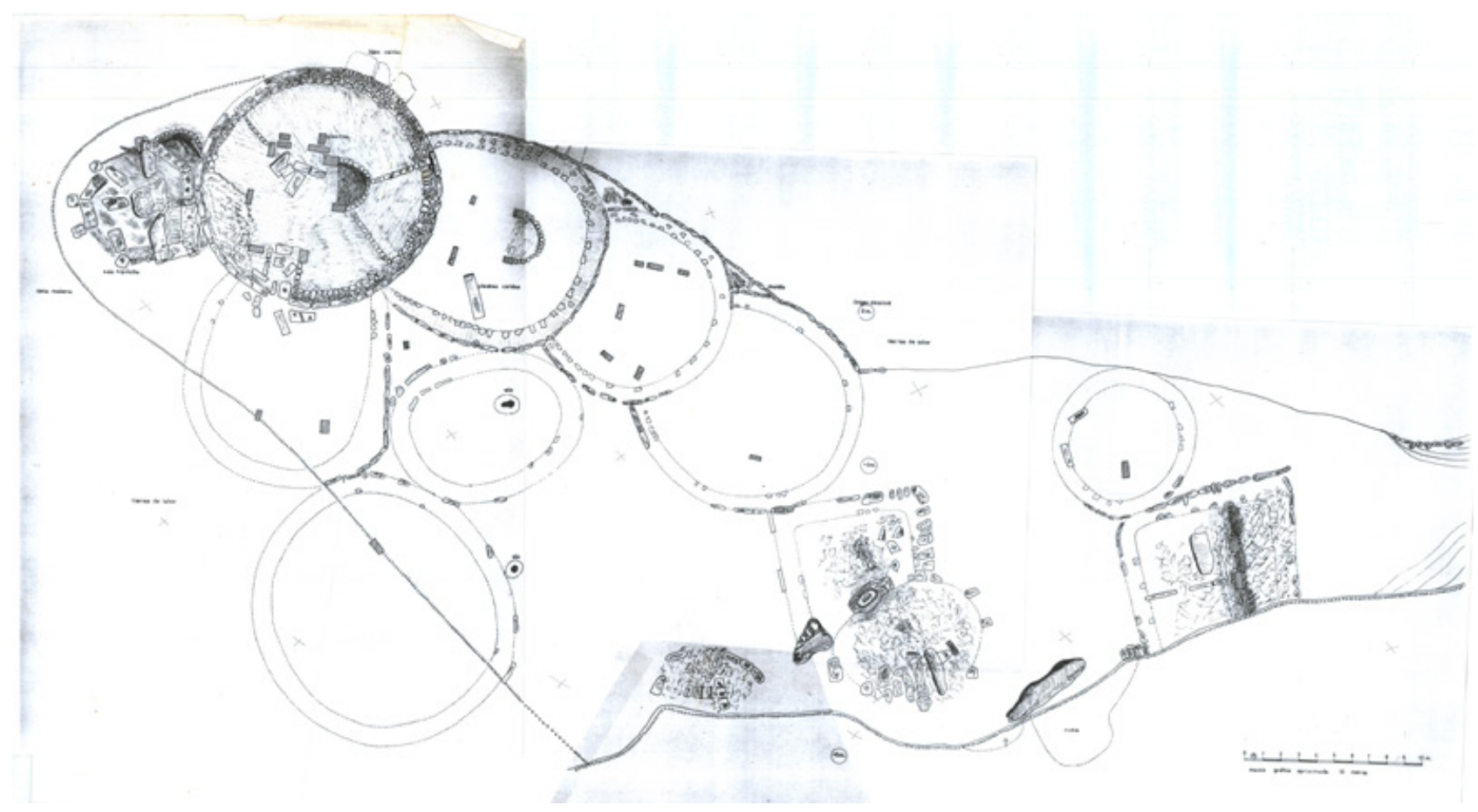

Figura 3: Copia de la planimetría original de Sant Vicenç d'Alcaidús realizada por Víctor Tolós (facilitada por J.C. de Nicolás i Mascaró).

Mientras se dibujaban las plantas pertinentes y se fotografiaba aquello que consideraban necesario, M. ${ }^{a}$ Lluïsa y el equipo decidieron practicar dos pequeños sondeos en Son Catlar y Talatí de Dalt. En el primer caso, se realizaron dos pequeñas catas de $3 \times 4$ metros en el interior del recinto amurallado, una cerca de la mitad del lienzo de poniente, próximo al recinto de taula; y la otra en un punto, hoy indeterminado, al sur. Esta última no tuvo ningún resultado, pues se halló la roca base a escasa profundidad (Serra, 1961a). Sin embargo, la estratigrafía (Serra, 1961b) que documentó en el sondeo de poniente fue la siguiente: a $30 \mathrm{~cm}$ de profundidad halló diversos bloques sin conexión entre sí; a $50 \mathrm{~cm}$ dio con un muro perimetral de un círculo, identificado como tal por su doble paramento con relleno de piedra; mientras que, finalmente, a $120 \mathrm{~cm}$ encontró sobre la roca madre las cenizas de un hogar, un amoló junto a él y un cuello completo de ánfora.

Por otra parte, en Talatí de Dalt, el sondeo $\left(\right.$ de $2 \mathrm{~m}^{2}$ ) se practicó en el interior del recinto de taula (1966a). La secuencia obtenida, de $1 \mathrm{~m}$ de profundidad, se resume en una primera capa de tierra vegetal, una segunda de cenizas con cerámica romana, y finalmente otra de tierra amarillenta con abundantes restos de fauna (Serra, 1961a). Sin embargo, resultó más prolijo el hallazgo de un recinto cubierto, desconocido anteriormente por su cubierta de piedras y vegetación. Su excavación también arrojó, según M. ${ }^{a}$ Lluïsa (1961a), una estratigrafía similar a las anteriores. Una primera capa de tierra vegetal daba paso a otra de tono oscuro con cerámica romana, finalizando, muy cerca de la roca base, con un pequeño estrato de apenas $10 \mathrm{~cm}$ de tierra oscura con cerámica talayótica y una bala de honda.

Con el fin del verano de 1959 llegó un pequeño parón en la actividad del grupo, retomándose en noviembre con un ambicioso proyecto, dirigido por la incombustible M. ${ }^{a}$ Lluïsa: la restauración de la naveta des Tudons. No entraremos en las vicisitudes de estos trabajos, que se dilataron hasta finales de año, cuando, aprovechando algunos días de Navidad, el equipo volvió a Menorca para realizar los levantamientos planimétricos de otros yacimientos menorquines, como las navetas de Rafal Rubí, Torre d'en Galmés y Sa Comerma de Sa Garita, Torralba d'en Salort, San Vicente de 
Cala'n Porter, (Serra, 1961a). Con ello se acabaron los dos años de plazo otorgados de la Ayuda March para el Estudio de la Edad del Bronce en las Islas Baleares, cuyos resultados, además de los publicados por M. ${ }^{a}$ Lluïsa a lo largo de los artículos ya citados, también pueden encontrarse parcialmente en la síntesis de LI. Pericot publicada posteriormente (1975) y en el informe inédito entregado a la Fundación Joan March (1960).

\section{Las campañas arqueológicas en los Círculos 2, 3 y 4 de Sant Vicenç d'Alcaidús $(1960,1961$ y 1966)}

Acabada la Ayuda March, M. ${ }^{a}$ Lluïsa se propuso continuar con las intervenciones en Sant Vicenç d'Alcaidús. Para ello contó con el beneplácito de las instituciones y sobre todo con un donativo económico de un titular privado, al que hace referencia en múltiples ocasiones con gratitud (Serra, 1961a; 1961d). No obstante, decidió no volver al Círculo 1, pues la consolidación de sus pilastras no se había llevado a cabo aún, y en su opinión ésta era una "pieza perfecta en su clase (...) creí mejor dejarla para cuando tuviera un conocimiento más completo de este tipo de monumentos" (1961b). Por otra parte, secante al primero y delimitado grosso modo en la campaña de 1959, el denominado Círculo 2 aparecía adosado al 1 y presentaba peores condiciones de conservación, con "pilastras caídas y las lajas del muro exterior desaparecidas en gran parte" (Serra, 1961a), por lo que su excavación no supondría a priori demasiados inconvenientes.

La campaña se inició a principios del verano de 1960. Durante los meses de julio y agosto se intervino en los denominados sectores Norte, Este y Sur, llegando a la roca madre en las tres zonas (Serra, 1961b). La estratigrafía (Serra, 1961a) se prolongó cerca de 1,20 m hasta llegar a la base, eliminando en primer lugar una capa de tierra vegetal de $30 \mathrm{~cm}$. El resto no presentó diferentes capas, según su directora, pero se ve alterada a $1,05 \mathrm{~m}$ de profundidad por el hallazgo de un conjunto de lajas planas, interpretado como un pavimento (Serra, 1961b), que separaría dos niveles de uso de la edificación. Ésta diferenciación sería a su vez confirmada por la cerámica talayótica recuperada en la estructura, que presentaba determinadas condiciones de dureza según se hallase por encima o por debajo del citado pavimento. La cerámica que apareció sobre el nivel de lajas era extraordinariamente "blanda", mientras que aquella recuperada a escasos $15 \mathrm{~cm}$ de la base, por debajo de las lajas, era notablemente dura (Serra, 1961a). Dentro de este repertorio, destaca el hallazgo de un vaso fragmentado con decoración de doble hacha en relieve (Pons, 2015). Por otra parte, la cerámica de importación recuperada, muy abundante en el Círculo 2 , parece no responder al patrón marcado por la separación del pavimento de lajas (Serra, 1962b). Los abundantes amolons recuperados Ilaman la atención de M. ${ }^{a}$ Lluïsa considerablemente, pues se hallan en grupo y ubicados generalmente en la zona central (Pons, 2015). Además de estos molinos de mano, también recupera proyectiles de honda y algunos percutores líticos (Serra, 1961a), siendo por tanto un conjunto heterogéneo de materiales muebles.

Sin embargo, será un elemento arquitectónico descubierto en esta campaña el que terminará

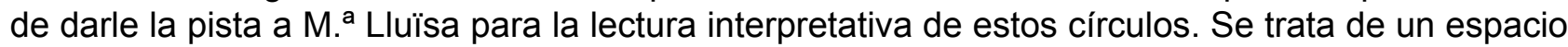
absidal, ubicado entre las dos pilastras orientales de la zona central del Círculo 2, es decir, exactamente igual que en el círculo anejo. Su sorpresa ante este hallazgo, que marcaba un patrón regularizado respecto a la estructura vecina, la hizo creer que se encontraba entonces ante una solución arquitectónica para sostener las pilastras, preguntándose al mismo tiempo por qué se ubicaba en uno de los laterales y no en algún extremo de la elipse del espacio central (Serra, 1961b) (Figura 4). Estos interrogantes quedarían sin embargo pendientes para la próxima campaña. Al llegar a la roca base en las zonas de intervención Este, Sur y Norte, M. ${ }^{a}$ Lluïsa documenta el modo de preparación del terreno previo a la construcción de la estructura y de nivelación del mismo para su pavimentación con el hallazgo de diversas lajas y piedras planas colocadas sobre los desniveles de la roca madre, previamente alisada (Serra, 1961a). 


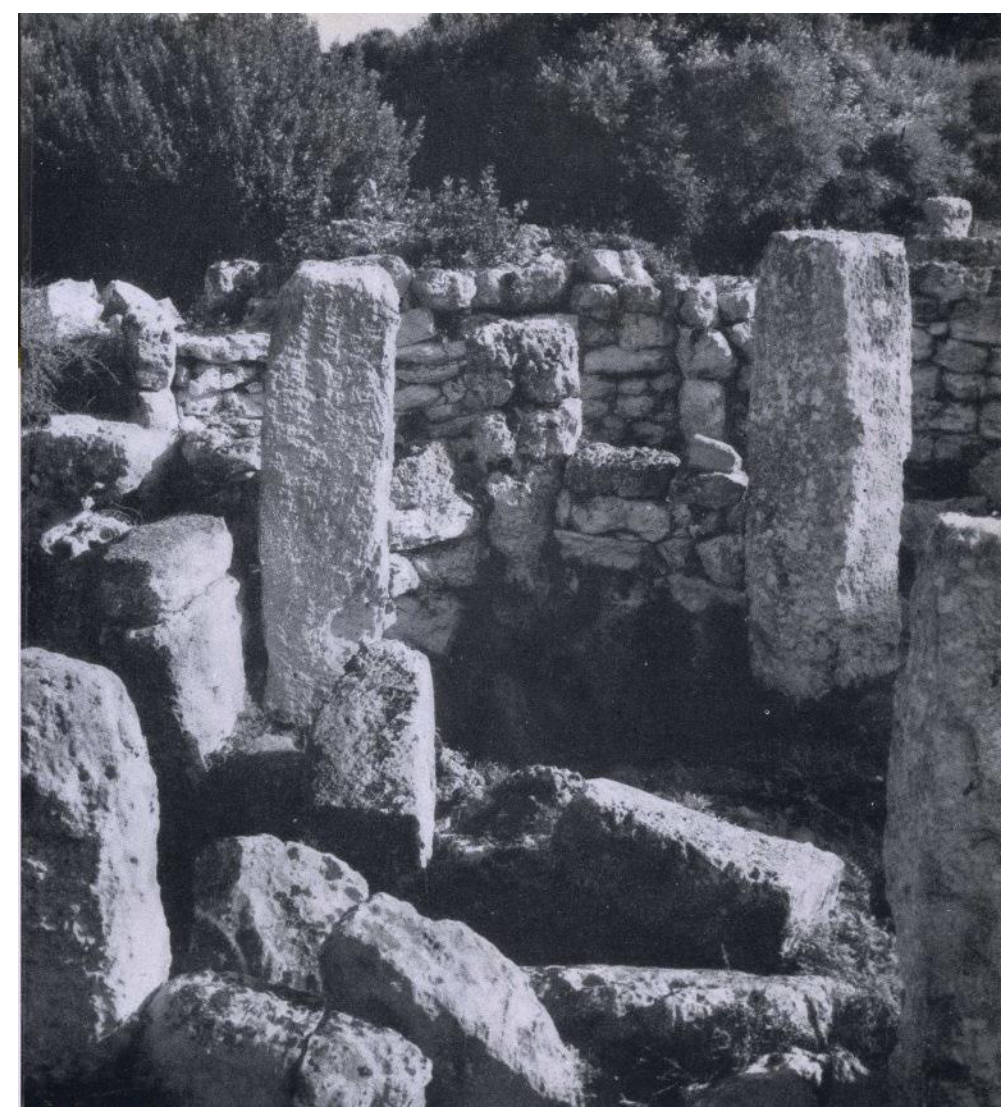

Figura 4: Vista del espacio absidal del Círculo 2. Fuente: Serra, 1964b, fig. 22.

Durante los meses de agosto y septiembre del año 1961 tuvo lugar la segunda campaña arqueológica en el Circulo 2. Las labores acometidas en esta campaña se dividieron en dos fases: una de reconstrucción del muro perimetral de la estructura circular; y la otra de excavación, finalizando los sectores Norte, Este y Oeste, así como el espacio central y otros ámbitos en la vertiente suroeste de la estructura (Serra, 1962b). La primera consistió fundamentalmente en la reubicación de las grandes lajas caídas del paramento exterior del muro perimetral (Serra, 1962b), trabajo concentrado especialmente en el sector oriental. Se intentó llevar a cabo la reconstrucción de las hiladas superiores, consiguiendo recuperar con cierta seguridad la primera de ellas con los bloques caídos a los pies del muro, pero no la segunda ante la falta de indicios suficientes para su reintegración.

La segunda fase, iniciada a mediados de agosto, se concentró en el espacio central de la estructura y en la parte occidental, además de los citados sectores que restaban por finalizar. Uno de los objetivos primordiales era la definición del ábside aparecido el año anterior. Su excavación mostró en primer lugar una hilera de piedras dispuestas en semicírculo ante el ábside (Serra, 1961b), ampliando el espacio y delimitándolo respecto al área central, en cuyo interior se halló un estrato de cenizas de $5 \mathrm{~cm}$ de espesor, que en algunos puntos traspasaba la barrera del muro semicircular. Entre la capa de cenizas y carbones aparecieron abundantes restos de fauna (ovicaprino, roedores y malacofauna); mientras que adosado a la pared interior del ábside se hallaron diversas piedras colocadas formando un banco caído, acompañado de numerosos fragmentos de cerámica púnica, como jarras y escudillas (Serra, 1965a) y talayótica (Serra, 1962b). Todo ello sirvió a M. ${ }^{a}$ Lluïsa para interpretar este espacio como el hogar familiar (Serra, 1961b; 1964a; 1965a), el espacio reservado para el fuego que proporcionaba calor y luz, además de una zona de preparado de alimentos.

Por otra parte, la excavación del patio central apenas aportó material mueble, salvo la aparición de nuevo de múltiples amolons, siguiendo la dinámica iniciada en la campaña del año anterior, y 
restos de cerámica autóctona e importada. Destaca, no obstante, el hallazgo de una estructura compuesta por dos lajas verticales paralelas escuadradas que sustentan una superior de igual factura, ubicada en el ángulo formado por los muros norte y oeste, "dando la impresión de tratarse de una mesa" (Serra, 1962b) y en cuyo interior se encontró un vaso de fondo alto (Figura 5). De nuevo como en el círculo anejo, la excavación del espacio central reveló la presencia de muros de pequeña envergadura que unían las pilastras y el ábside entre sí. No obstante, en el Círculo 2 se ha conservado mejor el sector septentrional y occidental de la estructura, permitiendo observar que estos muros realmente configuran otros espacios.

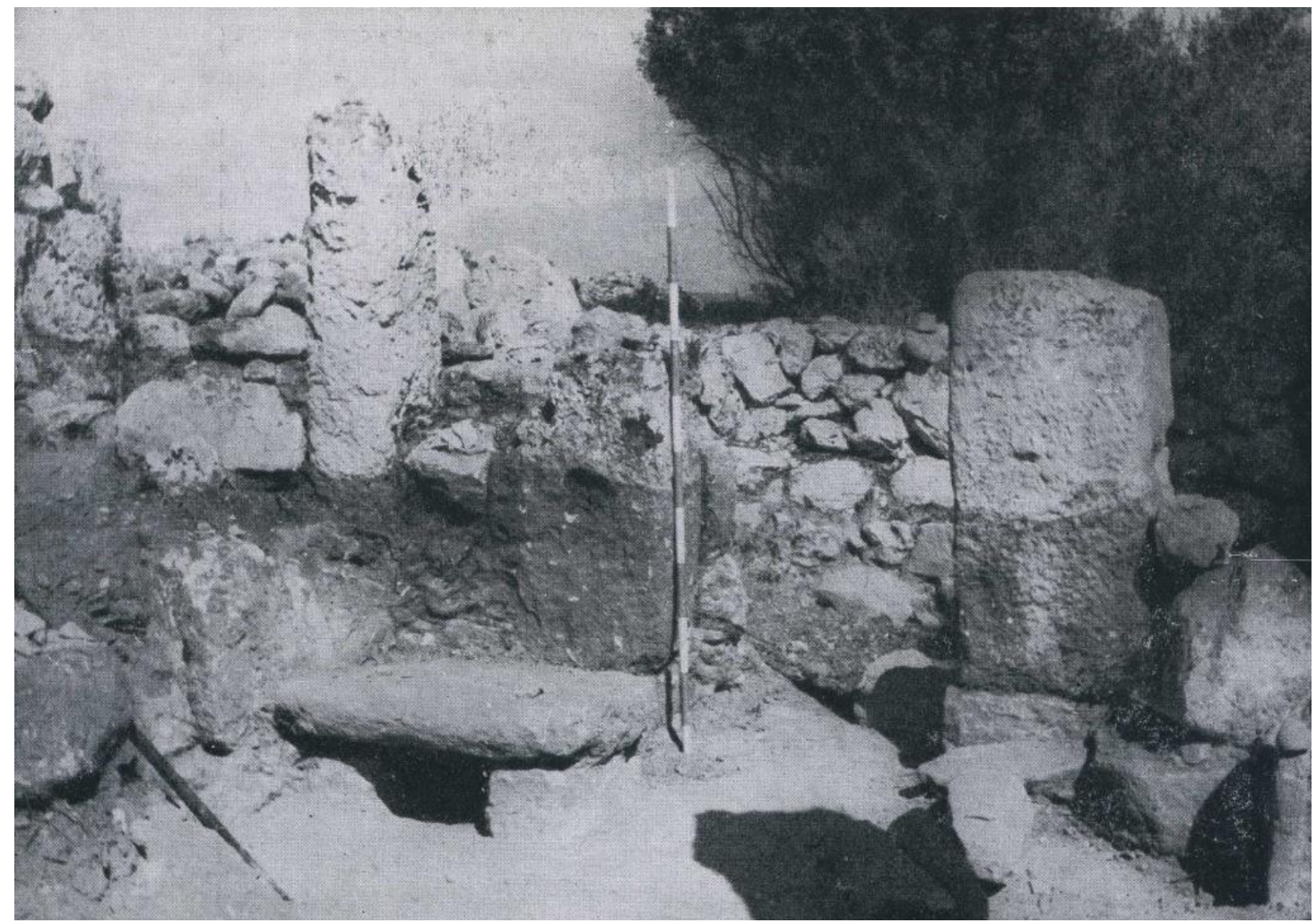

Figura 5: Fotografía del patio del Círculo 2 de Sant Vicenç d'Alcaidús donde se observa la estructura de lajas de piedra y el acceso a la estancia septentrional. Fuente: Serra, 1964a, fig. 14.

Al norte se delimitó una amplia zona a la que se accedería desde el patio central, cuya puerta monumental, realizada mediante dos grandes jambas monolíticas, recordaba a M. ${ }^{a}$ Lluïsa aquellas observadas en los recintos cubiertos de Talatí de Dalt (Serra, 1961b). Estas puertas serán parte de un estudio monográfico realizado a posteriori (Serra, 1965b). Por otra parte, en el sector occidental, las pilastras enmarcaban sendos vanos de accesos delimitados a su vez por jambas y umbrales monolíticos tallados, con escotaduras alargadas para insertar probablemente piezas de cerramiento (Serra, 1962b). Estos dan paso a dos habitaciones de planta rectangular, separados por un pequeño muro medianero. M. ${ }^{a}$ Lluïsa excavó la suroeste, atestiguando la excavación previa de la roca del suelo para su adaptación (Serra, 1962b), siguiendo el patrón observado en el patio central.

Con la excavación de 1961, apunta la directora de la intervención, quedaba revelada la constitución interior de los círculos (Serra, 1961b). Del Círculo 2 restaba por esclarecer su sector meridional, que presentaba graves problemas de conservación. Asimismo, no se había resuelto el problema de la cubierta de estas estructuras, si el patio se encontraba a cielo abierto o tal vez toda la estructura (Serra, 1962c). En cuanto a la cultura material mueble recuperada, contamos con los datos proporcionados por sus diarios, a falta de la publicación de las memorias de excavación. Predomina de nuevo la cerámica talayótica (olla, escudillas, vasos de fondo alto, etc.) y la cerámica 
púnica (ánforas, jarras, platos), acompañados de cerámica itálica e ibérica (Pons, 2015). Sin embargo, el material más abundante en proporción son los amolons, teniendo en cuenta que fueron cerca de 41 los ejemplares recuperados en la misma estructura.

No sería hasta 1966 cuando M. ${ }^{a}$ Lluïsa volvería a Sant Vicenç d'Alcaidús. Toda la información obtenida en las campañas anteriores fue suficiente para la elaboración de su hipótesis principal sobre los círculos menorquines. Por tanto, los años siguientes a la excavación del Círculo 2, M. $^{a}$ Lluïsa se dedicó a la redacción y publicación de sus trabajos de investigación y a participar en congresos de historia y arqueología, entre los que destaca la propia organización y celebración del X Congreso Nacional de Arqueología en Maó. De esta forma, volvió a Alcaidús en 1966 para acometer la excavación de los círculos observados ya durante la campaña de 1959. De estas intervenciones sólo nos quedan sus diarios (publicados parcialmente en Pons, 2015), alguna cita concreta en sus últimos trabajos y los informes administrativos inéditos (Serra, 1966c; 1966d). Los Círculos 3 y 4 plantearon una problemática diferente respecto a sus estructuras vecinas, casuísticas particulares que, por otra parte, sirvieron para cimentar sus teorías sobre los círculos y, a la sazón, de la ocupación histórica de Menorca.

El Círculo 3, adosado al 2 por el este, mostraba desde el principio complicaciones notables para su excavación. Gran parte de las lajas del paramento exterior del Círculo 2 estaban caídas sobre

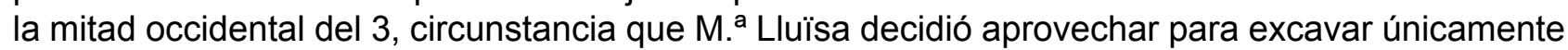
el sector oriental del círculo, con el objetivo de obtener una sección estratigráfica N-S del círculo. Por sus notas sabemos que se vislumbraban las pilastras del patio central y las jambas del vano de acceso a la estancia norte. Obtenida la sección, identifica y describe tres estratos (Pons, 2015), datados por los materiales aparecidos en cada uno de ellos: el inferior se situaría entre los siglos VIIVI a. C., por lo que se adscribiría al periodo talayótico; el intermedio datado entre los siglos II-I a. C.; y finalmente el superior, considerado como propiamente romano, que llegaría hasta el Bajo Imperio. Asimismo, dichos materiales que emplea para la datación relativa de la estructura se resumen en abundante cerámica romana y púnica, alguna moneda bajoimperial y escasa cerámica talayótica.

En peores condiciones se encontraba, a priori, el Círculo 4 del que apenas podía observarse parte del muro medianero del patio central que daba paso a la estancia septentrional, y una de las jambas que conformarían la puerta de acceso. Diversos apuntes en sus diarios de excavación, llevada a cabo en septiembre de 1966, apuntan la existencia de numerosos materiales romanos: cerámica itálica, monedas, tegulae, lucernas, etc. La zona de intervención fue el patio central, único sector que pudo delimitar, donde registró una estratigrafía similar al resto de círculos (Pons, 2015). Consistía en un primer nivel de tierra superficial con cerámica romana sobre un pavimento romano de opus signinum acompañado de terra sigillata, mientras que en cota inferior halló un estrato de tierra gris con cerámica romana y greco-púnica, y finalmente una capa de tierra amarillenta donde predominaba la cerámica talayótica y greco-púnica. Las últimas anotaciones del diario de campo de octubre de 1966 hacen referencia al hallazgo y excavación de estructuras propiamente romanas, las estancias cuadrangulares visibles aún hoy en Alcaidús, y una cisterna revestida de mortero hidráulico de adscripción romana. La clave interpretativa de esta última campaña, como recoge Pons (2015) del informe inédito de M. ${ }^{a}$ Lluïsa $(1966 \mathrm{~d}, 1)$, fue su asunción como estructuras que “(...) en época tardorromana (fueron) adaptadas a las nuevas necesidades y aún utilizados sus materiales para la construcción de aquellas casas citadas".

De forma paralela a todas estas campañas, antes incluso del inicio de la Ayuda March y realmente hasta su propio fallecimiento, M. ${ }^{a}$ Lluïsa Serra dedicó sus años a analizar exhaustivamente los datos que obtenía en las intervenciones arqueológicas que dirigía. Especialmente a partir de la excavación del Círculo 2, supo reunir todos los indicios que había ido documentando en los diversos yacimientos insulares (Torelló, Son Catlar, Talatí de Dalt, Torre d'en Galmés) para finalmente elaborar una hipótesis que sería, como ella misma reconoció, "una de la mejores aportaciones realizadas en estos últimos años" (1966d, 18) en el panorama de la prehistoria menorquina. Y es que se encontraba ante las viviendas de la sociedad prehistórica de Menorca. 


\section{Articulando la casa talayótica: interpretaciones, historiografía, formas y cronología}

No obstante, aquella certeza fue el resultado de un largo proceso de comprensión e interpretación de la información que fue acumulando desde el inicio de sus intervenciones arqueológicas, especialmente en Alcaidús. A lo largo de las publicaciones y congresos en los que participaba ya dejaba entrever aspectos fundamentales de su teoría posterior, como la organización espacial de los asentamientos prehistóricos (Serra, 1961a; 1961c; 1962b) o la importante presencia, y lo que ello podía significar, de un hogar central en cada círculo (Serra, 1961b). Ante la excavación de los diversos yacimientos en los que interviene, ella misma intentar encajar el panorama de todas estas estructuras, articulando un discurso que les diese sentido. Sin embargo, pronto observa cierta heterogeneidad ante la recurrencia de patrones, como el círculo de Torelló y los de Sant Vicenç d'Alcaidús, que comparten elementos constructivos, pero no la disposición de sus espacios; o el de Son Catlar, mucho más "simple" que los otros; mientras que los de Torre d'en Galmés sí son prácticamente iguales a los de Alcaidús (Serra, 1961b; 1964a).

Además de estos indicios, M. ${ }^{a}$ Lluïsa inició la investigación exhaustiva de estas estructuras, más allá del trabajo de campo, con la búsqueda bibliográfica de todas las referencias historiográficas de este tipo de estructuras (Serra, 1961b, 65-69; Serra, 1964a), base fundamental sobre la que cimentará su teoría. La primera referencia de los círculos data de principios del siglo XIX con la célebre obra de J. Ramis i Ramis, Antigüedades célticas de la isla de Menorca (1818). En ésta figuran una serie estructuras circulares en las inmediaciones de las atalayas (talayots), situadas en algunos yacimientos como Torelló o Biniaiet. Pone de manifiesto además que a corta distancia de estos se encontraban fácilmente gran cantidad de amolons, siendo éste un detalle importante para M. ${ }^{a}$ Lluïsa ante el hallazgo recurrente de estos objetos en sus excavaciones. Años después, É. Cartailhac (1892) describió y analizó algunos yacimientos menorquines, como Trepucó, Torretrencada, Son Catlar o Torralba, en su obra Monuments primitifs des îles Baleares. Entre diversas anotaciones, apunta la recurrencia de círculos de piedra en los poblados prehistóricos de la isla. Sin embargo, tanto Ramis como Cartailhac, incluyeron dentro de la categoría de círculos los recintos de taula, de los que citaban principalmente su pieza central, y a los que dedicaban mayor atención, debido probablemente su monumentalidad.

No será hasta El Arte Egeo en España (1908; 1910) de A. Vives Escudero donde se distinga netamente entre círculos sencillos y con taula, aunque siendo de nuevo estos últimos de mayor interés para el autor. Finalmente, una apreciación diferente, en la que M. ${ }^{a}$ Lluïsa fundamentará parte de sus hipótesis, es la de J. Hernández Mora, en Menorca Prehistórica (1922; 1923), que habla de "monumentos circulares de época decadente", diferenciándolos de las taulas, y apuntando que se construyen a expensas de las construcciones de sus alrededores. También como parte de la historiografía sobre la que trabajaba M. ${ }^{a}$ Lluïsa, destaca la obra de M. Murray. Esta egiptóloga inglesa llegó a Menorca en los años 30 del pasado siglo y excavó parte de los círculos de Trepucó, ubicados en las inmediaciones de la taula (1932; 1938); así como los de Sa Torreta de Tramuntana (1934).

Con este recorrido y todos los datos obtenidos en las sucesivas campañas arqueológicas, $M{ }^{a}{ }^{a}$ Lluïsa, por vez primera, en el marco del VII y VIII Congreso Nacional de Arqueología, caracteriza los círculos menorquines desde una perspectiva formal, basándose principalmente en Alcaidús (Serra, 1962; 1964a). Define una construcción de planta circular con un muro perimetral compuesto, por el interior, de hileras de piedra escuadrada, superpuestas por el sistema de falsa cúpula, y jalonadas de forma intermitente por pilastras verticales insertas en el muro. Por otra parte, en el exterior, el muro es de grandes lajas verticales que descansan sobre una base de piedras de la misma anchura pero más bajas, mientras que sobre las lajas se disponen de nuevo varias hileras de bloques escuadrados. Finalmente, entre ambos paramentos, un relleno de piedra y tierra. En el interior del círculo, destaca la presencia de seis pilastras (con basa y capitel) que forman una elipse central, cuyo eje N-S es el más largo. En el extremo septentrional de la elipse, entre dos pilastras, se abre un vano compuesto por dos jambas que da acceso a una gran habitación delimitada por pequeños 
muretes radiales que unen las pilastras con el muro perimetral.

Próxima al acceso de esta habitación, entre una de las pilastras de acceso y la contigua por el lado oriental, se halla un ábside construido mediante un muro cóncavo uniendo los citados elementos estructurales, de bloques escuadrados con un pilar central. En este muro cóncavo, en la parte inferior, se dispone un pequeño banco adosado formado por lajas de mediano tamaño dispuestas en vertical y horizontal. Por otra parte, en la sección occidental del círculo, de nuevo mediante pequeños tabiques medianeros formados por mampostería trabajada, se unen las pilastras y se compartimenta el espacio, creando dos estancias de planta pseudo rectangular, cuyo vano de acceso se compone de dos jambas formadas por lajas y un umbral monolítico tallado con hendidura central. En cuanto al resto de la estructura, se compone de un gran espacio cuya única particularidad es constituir un fondo ovalado en el extremo donde entra en contacto con el hogar absidal.

Una vez caracterizada, grosso modo, la estructura principal de los círculos, M. ${ }^{a}$ Lluïsa afronta diversas cuestiones que resolver, ya planteadas anteriormente a lo largo de las campañas de excavación. La primera de ellas es el sistema de cubierta de los círculos, problemática a la que llegó a dedicarle una publicación monográfica (1962c). A priori la respuesta le parece evidente, imaginando una cubierta de madera y elementos vegetales típica. Pero la autora se cuestiona si no podría tratarse de un techo completamente de piedra, atendiendo al panorama observable en otros yacimientos menorquines. Ello la lleva a hacer un estudio exhaustivo de los sistemas de cubierta detectados a lo largo de los asentamientos prehistóricos menorquines. En el aborda los célebres talayots y navetas, de los que destaca los de Son Catlar y San Agustí Vell por su cierre de falsa bóveda mediante aproximación de hiladas y cierre mediante lajas, o de columnas y lajas radiales (Serra, 1962c). No obstante, el abismo morfológico y funcional entre estas estructuras y las que le atañen, la hacen cambiar el objeto de comparación.

Se centra entonces en las llamadas salas hipóstilas y recintos cubiertos. De éstas pone de relieve la similitud de los elementos técnicos que constituyen ambas tipologías: columnas y capiteles (Serra, 1962c). Las columnas se conforman por diversos tambores trabajados de forma irregular, o de piedras monolíticas generalmente troncocónicas invertidas o de sección rectangular. Por otra parte, los capiteles presentan una articulación más heterogénea, documentándose bloques de piedra de forma circular generalmente, pero también cuadrangular o incluso trapezoidal. El sistema de cubierta se basaría por tanto en la disposición de grandes lajas de piedra dispuestas de una columna a otra, que en muchos casos serán pilastras (por estar adosadas a un muro). Ejemplos principales de su análisis comparativo son Talatí de Dalt, Torralba d'en Salord o Son Saura (Serra, 1962c). No obstante, más allá de recoger las distintas manifestaciones observadas, no concreta ninguna de ellas para el caso de los círculos ante la falta de indicios suficientes para decantarse por una u otra.

Analizando estos yacimientos para dar respuesta al problema de la techumbre, M. ${ }^{a}$ Lluïsa atenderá otra de las particularidades de los círculos: las puertas. En los recintos cubiertos de Talatí observa que las vanos de acceso a las diferentes estancias están constituidos por sendas jambas y un dintel, piezas rectangulares y escuadradas. Pero la característica principal es que las piezas aparecen en parejas, se trata realmente de cuatro jambas y dos dinteles, separados apenas $20 \mathrm{~cm}$ entre sí (Serra, 1965b). Esta particularidad está presente también en los círculos de Sant Vicenç d'Alcaidús y Biniaiet, específicamente en el acceso que da paso a la habitación septentrional. Sin embargo, más allá de su presencia, que M. ${ }^{a}$ Lluïsa vincula con el mundo griego del Mediterráneo oriental (como se verá más adelante con otros elementos), no avanza más en sus interpretaciones, quedando pendiente si se trata de un elemento técnico o ritual, o sí está presente en todos los asentamientos menorquines, o si incluso es exclusivo de la comarca situada en Maó y Alaior (Serra, 1965b).

Producto de la tradición académica del momento, caracterizada principalmente por la obra de Vives Escudero (1910) y Martínez Santaolalla (1935) en el caso de Menorca, e imbuida también durante su formación universitaria de estas corrientes interpretativas, M. ${ }^{a}$ Lluïsa centró su búsqueda 
de influencias y contextos similares de la arquitectura menorquina en el mundo prehelénico del Mediterráneo central y oriental, concretamente en las islas de Malta, Chipre, Creta, Sicilia y parte de Grecia. Además de su exhaustiva investigación, realizó un viaje por todos estos escenarios durante el verano de 1963 para observar de primera mano el registro arqueológico de estos territorios, y cuyos resultados fueron expuestos de forma monográfica en una comunicación y publicación posterior (Serra, 1964a). Con los ojos de la historiografía que la precedía, visitó Micenas para cotejar las comparaciones que había hecho Vives Escudero entre los círculos menorquines y las tumbas de los Átridas, especialmente por los paramentos de grandes lajas (Serra, 1964a). Sin embargo, fue en Malta donde halló más similitudes, concretamente en los yacimientos de Hagar Quim, Tarxien, Mnajdra y Borg. En ellos halló estructuras circulares con paramentos de lajas, algunas con pilastras insertas en los muros y puertas dobles, pero los malteses eran de mayores dimensiones, formaban complejas estructuras concéntricas y los paramentos de lajas verticales también se hallaban en la cara interior de las construcciones (Serra, 1964a). Además, M. ${ }^{a}$ Lluïsa era plenamente consciente de que la funcionalidad de estas estructuras y sus cronologías distaban mucho de la de los círculos menorquines, siendo su análisis puramente comparativo a nivel morfológico (Serra, 1964a).

Uno de los principales artículos de M. ${ }^{a}$ Lluïsa Serra, por su importante contribución al respecto, que sigue vigente a día de hoy, fue su participación en la obra Arquitectura megalítica y ciclópea catalano-balear (1965a). En ella aborda un estado de la cuestión de todas las manifestaciones arquitectónicas de la Menorca prehistórica, caracterizando todas sus estructuras, incluyendo navetas, murallas, círculos y talayots. Una de las partes más importantes es la definición, de forma explícita, de dos tipos de aparejo presentes en la mayoría de yacimientos menorquines, así como la caracterización de todos los elementos constituyentes y soluciones arquitectónicas de la prehistoria menorquina (columnas, falsa bóveda, puertas dobles, etc.). Volviendo al primer aspecto, es en este artículo donde define lo que denomina aparejo talayótico y aparejo de lajas verticales (Serra, 1965a). Esta división ya quedó patente en publicaciones anteriores (Serra, 1961b; 1964a), pero es ahora cuando la hace explícita. El talayótico, llamado así por ser el empleado siempre en talayots, se forma mediante hiladas horizontales de bloques de piedra escuadrada (de forma heterogénea), superpuestas hasta llegar a la altura deseada; mientras que el de lajas verticales se compone de un pequeño zócalo de bloques cuadrados sobre los que se disponen grandes lajas cuadrangulares en posición vertical (algunos más horizontales o cuadrados) y finalmente se remata con varias hiladas de bloques escuadradas de aparejo talayótico.

La tipificación de los aparejos encierra una cuestión pendiente en la investigación de la autora: la cronología de los círculos. Como ya hemos mencionado anteriormente, en función de la cerámica hallada durante las excavaciones de Alcaidús, Talatí o Son Catlar, la presencia de cerámica talayótica acompañada de ánforas y recipientes púnicos sobre la roca madre en la que se asientan las estructuras lleva a datar su erección en el siglo VI a.C como mínimo (Serra, 1964a; 1965a). Ante la incapacidad de avanzar en la datación mediante cerámica, M. ${ }^{a}$ Lluïsa intenta otorgar diferentes fases cronológicas a estos paramentos (1961b). Para ello, parte de las notas de Hernández Mora, quien, recordemos, apunta que los círculos son de "época decadente" y se construyen a expensas de las estructuras de sus alrededores (1924). Por otra parte, durante la campaña de 1959, se fija en algunos indicios especialmente ilustrativos: en Talatí de Dalt observa que algunos círculos construidos mediante aparejo de lajas verticales tienen como base los restos de una construcción anterior; y en Son Catlar, la gran muralla que rodea el yacimiento es de aparejo de lajas verticales, amortizando en su vertiente noreste uno de los talayots del poblado (Serra, 1964a; 1965a). Por tanto, todo ello la lleva a proponer que el aparejo talayótico es anterior en el tiempo al de lajas verticales. Sin embargo, también apunta que algunos círculos están construidos íntegramente con aparejo talayótico, como en Sant Agustí Vell y Torre d'en Galmés (1961b; 1964a), por lo que no termina de encontrar una solución satisfactoria al problema planteado.

Finalmente, hay una cuestión, la más importante a la sazón, que quedaba aún por resolver para M. ${ }^{a}$ Lluïsa: ¿qué son exactamente los círculos talayóticos? Aunque desde muy pronto apuntó sutilmente qué funcionalidad tendrían estos círculos, no será hasta más adelante en el tiempo 
cuando dé una explicación histórica y hermenéutica de estas construcciones. Con la identificación del hogar familiar (Serra, 1961b), la estructura que lo contiene adquiere connotaciones indisociables a la domesticidad y vida cotidiana, entendiendo que las familias talayóticas vivirían allí. Por otra parte, ya observó que estas estructuras eran las más recurrentes en los asentamientos prehistóricos menorquines, creando esa "trabazón de círculos, de diverso diámetro y estructura, sirviendo de fondo y aglutinante (...)" (Serra, 1964a, 246), asumiendo que se trata del tejido urbano de cada poblado, cuya unidad mínima es, por ende, la vivienda. La identificación de los círculos como casas ha quedado patente en numerosas publicaciones en las que afirmaba rotundamente que estos círculos eran las viviendas de la sociedad prehistórica de Menorca (Serra, 1965; 1966b; etc.), mientras que en otras lo hacía de forma más velada, citando a las comunidades insulares como "los habitantes de los círculos" (Serra, 1964a, 16). Esta afirmación es, como ya ha quedado expuesto anteriormente, completamente novedosa hasta el momento, siendo, como ella misma predijo (Serra, 1966b), la mayor aportación al conocimiento de la prehistoria menorquina en aquel momento. Cabe destacar finalmente que en el libro que preparaba junto con otros especialistas sobre la historia de Menorca, que no pudo acabar a tiempo por su temprana muerte pero que vio la luz años después gracias a sus coautores (Serra et al., 1977), Serra profundizó en la interpretación espacial de las diferentes estancias que componen el círculo de habitación canónico. Además del patio central y del hogar familiar, habla de un probable uso cúltico ("santuario familiar") situado en la estancia septentrional apoyándose en el tipo de cultura material mueble hallada (1977). No obstante, fue una teoría que no pudo desarrollar exhaustivamente por su inminente fallecimiento, quedado el texto inconcluso.

Además del reconocimiento de los círculos como las viviendas propias de las comunidades prehistóricas de la isla, Serra intentó finalmente construir el discurso histórico que daría explicación a estas estructuras. De esta forma, prácticamente en las postrimerías de su vida, propone (Serra, 1967d) que, de forma similar al panorama observado en la cultura nurágica sarda, la sociedad talayótica erguiría estas estructuras turriformes, destinadas a soportar una vivienda notable ocupada por la élite social. La mayor parte de la población viviría en casas mucho más modestas, agrupadas en torno al talayot central. Sin embargo, esta situación se vería profundamente alterada entre los siglos VII - VI a. C. con la llegada de griegos y púnicos que verían en la isla un importante mercado para sus intereses. A su vez, la introducción de sus productos y los beneficios de su comercio con la población insular conllevaron la progresiva elevación del nivel de vida de estas comunidades, elevando su poder económico. Ello se vería reflejado en la transformación de sus modestas viviendas en grandes círculos, que debían ser una simulación de las que se hallaban en la cumbre de los talayots. Las relaciones propias de esta sociedad, a nivel estructural, fueron también una preocupación científica para la autora. En este aspecto, planteaba (Serra, 1964b) que la población que residía en los círculos podía estar bajo el yugo de aquella pequeña parte de la sociedad que vivía en lo alto de los talayots, siéndoles negada la capacidad de participar en las transacciones comerciales con los coetáneos del Mediterráneo. Este hecho sería el que jugaría en contra de esa élite social con la intensificación de los contactos con las comunidades exógenas. No obstante, al igual que en el caso anterior, éstas y otras muchas fueron preguntas a las que M. ${ }^{a}$ Lluïsa no pudo dar respuesta definitiva, dejando abierta la investigación sobre aquellas gentes prehistóricas, a las que dedicó vehementemente toda su vida, hasta el último esfuerzo.

\section{Reflexiones finales: el legado de Maria Lluïsa Serra Belabre}

Pericot empieza su libro con una dedicatoria: "A la memoria de María Luisa Serra Belabre, a la que tanto debe la prehistoria balear" $(1975,1)$. No le falta razón, y este trabajo ha intentado

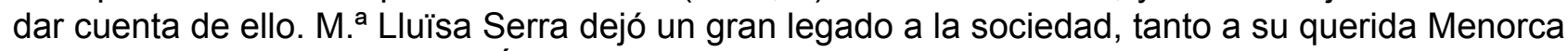
como al resto de la población. Éste se compone de grandes obras, como la erección de bibliotecas municipales y centros culturales (Orfila, 2012), pero también de numerosos trabajos escritos que materializan todo el patrimonio cultural de Menorca. Todos sus logros, en cualquier ámbito de todos los que trabajó, constituyen hoy la base de la vida cultural menorquina. Y la arqueología, como 
uno de sus campos predilectos, no es una excepción. Toda historiografía es fundamental para la comprensión de la historia de la isla, y la obra de M. ${ }^{a}$ Lluïsa es un claro ejemplo de ello. Fruto de su enorme pasión e inagotable espíritu, su bibliografía es hoy clave para comprender la prehistoria menorquina, constituyendo un cimiento indispensable para cualquier investigación en nuestros días.

Muestra particular de ello es Sant Vicenç d'Alcaidús y los llamados círculos talayóticos. Su bibliografía sigue siendo el punto de partida para cualquier aspecto relacionado con estas estructuras, pues aunque se haya avanzado en la caracterización de estas viviendas, la estructura teórica fundamental es la que ella formuló hace años, vigente en la actualidad. Parte de las cuestiones que planteó a lo largo de sus trabajos son ahora líneas de estudio abiertas y articulan los ejes del debate científico. Son paradigmáticos en este sentido tres grandes problemáticas inconclusas que ya inició M. ${ }^{a}$ Lluïsa: la cronología de los cercles, especialmente ante las imprecisiones arrojadas por las dataciones radiocarbónicas; los cambios en el modelo doméstico reflejados en las formas constructivas, es decir, el empleo de las diferentes técnicas constructivas y las connotaciones cronológicas de su uso; y otras preguntas aún problemáticas, como la cubierta de las viviendas, las funciones de las salas hipóstilas o el mismo uso y distribución de los espacios que conforman el ámbito doméstico de las comunidades prehistóricas menorquinas.

La identificación de los círculos con las viviendas de las comunidades prehistóricas de Menorca fue indudablemente un gran avance para la historia insular. No obstante, la lectura social e histórica del proceso de creación de estas estructuras ha virado desde las últimas líneas de la autora. Su lectura, entendiendo las casas como una imitación de grandes casas ubicadas en lo alto de los talayots, ha caído en desuso por la falta de argumentos. No obstante, actualmente se han realizado otras lecturas sociales de los espacios domésticos que han permitido ir más allá en la propia caracterización de estas sociedades del Postalayótico o Talayótico Final (550-123 a. C.), identificando aquellos elementos que denotarían rasgos comunes en los grupos domésticos que habitan estas casas (Salvà y Hernández-Gasch, 2007; Hernández-Gasch, 2011; Calvo y Guerrero, 2011; Carbonell, 2012; entre otros). Pero las causas intrínsecas que actuaron en el seno de estas comunidades para que materializaran este tipo de viviendas, sigue siendo una problemática pendiente. En este sentido, una línea de investigación actual aboga por continuar, aunque con una perspectiva teórica diferente, la senda marcada por M. ${ }^{a}$ Lluïsa al inferir que fue el contacto de la población autóctona con los agentes externos lo que provocaría un cambio trascendental en la forma de habitar de estas comunidades (Prados et al., 2015; Torres, 2016), si bien no de forma unilateral, sino como una conjunción de factores, marcada por la desigualdad y la lucha de poder en el seno de la sociedad prehistórica menorquina.

En cualquier caso, M. ${ }^{a}$ Lluïsa Serra Belabre fue sin lugar a dudas una mujer excepcional que trabajó hasta el final de sus días para conocer a esas gentes que habitaron círculos y talayots. Su vehemencia en la consecución de los medios necesarios para iniciar y desarrollar sus trabajos fue clave para la ejecución de sus proyectos. Para ello, desde el primer momento centró gran parte de sus esfuerzos en involucrar a todos los agentes necesarios: el mundo académico, las instituciones políticas $\mathrm{y}$, por supuesto, a la sociedad menorquina. $\mathrm{Y}$ es que, como historiadora, supo desde el principio que el valor de su profesión radicaba en eso que hoy se denomina transferencia, es decir, en devolver a la sociedad aquello que le pertenece: su pasado.

\section{Bibliografía}

Calvo, M. y Guerrero, V. (2011). La cultura Postalayótica (650/550-123 aC). En Calvo, M. y Aguareles, A. (coord.), Calvià. Patrimonio cultural (Vol. I) (pp. 113-146). Calvià: Ed. Fundación Calvià.

Carbonell, M. (2012). El Cercle 7 de Torre d'en Galmés. Estudi d'una estructura domèstica del segle III aC a Menorca. (Trabajo Fin de Máster). Universitat de Barcelona.

Cartailhac, É. (1892). Monuments primitifs des îles Baleares. Toulouse : Ed. Privat.

Hernández, J. (1922). Menorca prehistórica. Revista de Archivos, Bibliotecas y Museos, 1, 45-68.

Hernández, J. (1923). Menorca prehistórica II. Revista de Archivos, Bibliotecas y Museos, 3, 1-33. 
Hernández-Gasch, J. (2011). Privatització i diversificació de l'espai domèstic en la societat balear de l'Edat del Ferro. En Gual, J. (coord.), III Jornades d'Arqueologia de les Illes Balears (Maó, 3 i 4 d'octubre, 2008) (pp. 43-62). Maó: Consell Insular de Menorca.

Martínez Santaolalla, J. (1935). Elementos para un estudio de la cultura de los talayots en Menorca. Actas y Memorias de la Sociedad Española de Antropología, Etnología y Prehistoria, 14, 5-66. Murray, M. (1932). Trapucó. Part I. Cambridge Excavations in Minorca. Cambridge: Ed. Quaritch. Murray, M. (1934). Sa Torreta. Cambridge Excavations in Minorca. Cambridge: Ed. Quaritch. Murray, M. (1938). Trapucó. Part II. Cambridge Excavations in Minorca. Cambridge: Ed. Quaritch. Orfila, M. (2012). María Luisa Serra Belabre (1911-1967). Una precursora de su tiempo: arqueóloga, archivera, bibliotecaria, directora de museo, animadora cultural. ARENAL, 19 (1), 201-225.

Pericot, LI. (1975). Las Islas Baleares en los tiempos prehistóricos. Barcelona: Ed. Destino

Pericot, LI., Serra, M. L. (1960). Estudio de la Edad del Bronce en Baleares, Menorca. Informe inédito.

Petrus, M. (1968). María Luisa Serra Belabre (1911-1967). Ampurias, 30, 387-389.

Pons, J. (2015). Les cases talaiòtiques de Sant Vicenç d'Alcaidús (Alaior-Menorca) : la seva excavació a través dels diaris de camp de na M. Lluïsa Serra Belabre. En CIME (coord..). L'entreteixit del temps: Miscel/lània d'estudis en homenatge a Lluís Plantalamor Massanet (pp. 323-336). Maó: Consell Insular de Menorca.

Prados, F., Nicolás, J. C. D., Jiménez, H., Martínez, J.J. y Torres, O. (2015). Culturas arquitectónicas púnicas. Menorca como laboratorio de análisis. En A. Martínez y G. Graziani (coord.), VI Jornades d'Arqueologia de les Illes Balears (pp. 185-193). Formentera: Consell Insular de Formentera.

Ramis, J. (1818). Antigüedades célticas de la isla de Menorca desde los tiempos más remotos hasta el siglo IV de la Era Cristiana. Mahón: Imprenta Pedro Antonio Serra.

Salvà, B., y Hernández-Gasch, J. (2009). Los espacios domésticos en las Islas Baleares durante las Edades del Bronce y del Hierro. De la sociedad Naviforme a la Talayótica. En M. C. Belarte (coord.). L'espai domèstic i l'organització de la societat a la protohistòria de la Mediterrània occidental (1er millenni aC). Actes de la IV Reunió internacional d'Arqueologia de Calafell (pp. 299-322). Calafell: Universitat de Barcelona.

Serra, M. L. (1959). Una nueva basílica paleocristiana en Menorca. En Actas del V Congreso Nacional de Arqueología (234-239). Murcia

Serra, M. L. (1961a). De arqueología menorquina. Revista de Archivos, Bibliotecas y Museos, 69, 951-967.

Serra, M. L. (1961b). De arqueología menorquina: círculos. Revista de Menorca, 73 (3), 65-74.

Serra, M. L. (1961c). Limpieza y excavación de la estación talayótica de Alcaidús (Menorca). En Actas del VI Congreso Nacional de Arqueología (Oviedo, 1959) (pp. 122-125). Oviedo: Universidad de Zaragoza.

Serra, M. L. (2 de enero de 1961d). Actividades arqueológicas en 1960. Diario de Menorca. p. 24.

Serra, M. L. (1962a). Jerónimo de Zurita y la historiografía menorquina. En Actas del VII Congreso de Historia de la Corona de Aragón (pp. 145-146). Barcelona: Universitat de Barcelona.

Serra, M. L. (1962b). Informe sobre los trabajos realizados en la estación megalítica de San Vicente de Alcaidús (término de Alayor de Menorca). Agosto - septiembre 1961. Noticiario Arqueológico Hispánico, 6 (Cuadernos 1-3), 90-92.

Serra, M. L. (1962c). Monumentos de Menorca con cubierta de piedra. En Actas del VII Congreso Nacional de Arqueología (Barcelona, 1960) (pp. 173-177). Barcelona: Universitat de Barcelona.

Serra, M. L. (1963). El ilustrísimo Señor Don Juan Flaquer y Fábregues, 1877-1963. Revista de Menorca, 75 (1), 27-30.

Serra, M. L. (1964a). Los círculos de Alcaidús: su relación con los monumentos de Malta. En Actas del VIII Congreso Nacional de Arqueología (pp. 243 - 257). Sevilla-Málaga: Universidad de Sevilla.

Serra, M. L. (1964b). Menorca, pedra i arqueologia. En J. Leonard (coord.), Menorca, l'illa 
desconeguda (pp. 12-20). Barcelona: Ed. Barna.

Serra, M. L. (1965a). Arquitectura ciclópea menorquina. En Arquitectura megalítica y ciclópea catalano-balear (pp. 151-172). Barcelona: Delegación Barcelona del CSIC.

Serra, M. L. (1965b). De arqueología menorquina: puertas de elementos dobles. Revista de Menorca, 77 (3), 279-287.

Serra, M. L. (1966a). Contribución al estudio de las taulas, Talatí y Torrellafuda. En Actas del IX Congreso Nacional de Arqueología (Valladolid, 1965) (pp. 175-190). Valladolid: Secretaría General CNA.

Serra, M. L. (1966b). De la Menorca prehistórica: los círculos de Alcaidús. Diario de Menorca. Barcelona.

Serra, M. L. (1966c). Informe sobre los trabajos realizados en Sant Vicente de Alcaidús, septiembreoctubre 1966. Informe inédito.

Serra, M. L. (1966d). Actividades de la Delegación Insular de Excavaciones de Menorca. Informe inédito.

Serra, M. L. (1967a). Distribución de tierra después de la conquista de Menorca por Alfonso III: el "Hereu.". Maó: Casa de Cultura de Maó.

Serra, M. L. (1967b). Repercusión de la Guerra de Sucesión en la economía menorquina. En Homenaje a Jaime Vicens Vives (pp. 654-666). Barcelona: Universitat de Barcelona.

Serra, M. L. (1967c). Basílica cristiana de la Isla del Rey (Mahón). En Actas de la $1^{a}$ Reunión Nacional de Arqueología Paleocristiana. Vitoria: Obra Cultural de la Caja de Ahorros Municipal de la Ciudad de Vitoria.

Serra, M. L. (1967d). X Congreso Nacional de Arqueología. II Circular y guía. Maó: Ajuntament de Maó.

Serra, M. L., Roselló-Bordoy, G., y Orfila, J. A. (1977). Historia de Menorca. Mahón: Ed. Rafel Timoner Sintes.

Torres Gomariz, O. (2016). Caracterizando el Postalayótico balear (550-123 a. C.): arquitectura doméstica y sociedad bajo órbita púnica. En E. Cutillas (coord.). La diversidad en la investigación humanística. V Jornadas de Investigación de la Facultad de Filosofía y Letras de la Universidad de Alicante (Alicante, 26 y 27 de marzo de 2015) (pp.191-198). Alicante: Facultad de Filosofía y Letras.

Vives, A. (1908). El arte egeo en España. Cultura Española, 12(11), 1033-1063.

Vives, A. (1910). El arte egeo en España II. Revista de Archivos, Bibliotecas y Museos, 22 (5-6), 397-420. 


\section{Panta Rei}

PANTA REI es una revista digital de investigación orientada a la Historia y otras ciencias afines. Su principal objetivo es la transmisión del conocimiento científico, dando una oportunidad también a los jóvenes investigadores que quieren abrirse camino en el estudio de las ciencias humanas y sociales. Se compone de estudios originales relacionados con la disciplina histórica así como su didáctica y difusión. Las diferentes secciones que componen la revista son: artículos de investigación, entrevistas a profesionales, recensiones de monografías de actualidad y crónicas de congresos o eventos científicos relevantes.

Todos los artículos publicados son objeto de un proceso de revisión a cargo de un mínimo de dos evaluadores, que se consideran expertos en el ámbito temático del artículo propuesto. Nuestro deseo es poder ofrecer unos contenidos rigurosos, de calidad y de interés.

EI CEPOAT (Centro de Estudios del Próximo Oriente y la Antigüedad Tardía de la Universidad de Murcia) es la institución encargada de la coordinación y gestión de la revista, desde donde anualmente se lanzará la convocatoria para aquellos que estén interesados en publicar sus trabajos, siempre relacionados con la Historia, Arqueología, Historia del Arte, Didáctica de las Ciencias Sociales, etc.

PANTA REI is a digital journal focused on History and other sciences related to it. Its main objective is the transmission of scientific knowledge by giving also an opportunity to young researchers who want to make their way in the study of human and social sciences. It is composed by original studies related to History, as well as its didactics and promotion. The different sections of this journal are: research articles, interviews to professionals, recensions on monographs about current issues and reports about congresses or relevant scientific events.

All the articles published are subject to a revision process carried out by a minimum of two reviewers who are considered to be experts in the field of the article proposed. Our wish is to offer rigorous contents with quality and being of interest to the reader.

CEPOAT (Centre of Studies of the Middle East and Late Antiquity of the University of Murcia) is the institution in charge of the coordination and management of this journal. This is the centre from where the call for papers will be launched for all the people interested in publishing their papers, always related to History, Archeology, Art History, Didactics of the Social Sciences, etc. 


\section{Normas de Publicación}

El autor se compromete a enviar trabajos originales, que no se encuentren publicados en otras revistas ni en otros idiomas. Así mismo, el mismo artículo no podrá ser presentado en otras revistas mientras dure el proceso de evaluación.

\section{Envío y presentación de originales}

Los artículos se enviarán exclusivamente a través del correo electrónico a la dirección pantarei@um.es. Los textos serán enviados en formato DOC y las imágenes en formato JPEG o TIFF, y con un tamaño mínimo de 2000 px. Éstas no aparecerán incorporadas en el texto, sino enviadas en archivo aparte y correctamente numeradas según su posición en el texto. Junto al trabajo, se rellenará y enviará un documento aparte en el que se especifiquen los datos del autor siguiendo el modelo disponible en la página Web de la revista.

Para la redacción de los trabajos se tendrá en cuenta el Manual de la American Psychological Association, en su sexta edición. La extensión máxima de los trabajos será de 30 páginas. La tipografía será Arial 11, con interlineado sencillo y sin espacio alguno entre párrafos. El texto deberá ir justificado a ambos márgenes y sin sangría en los primeros párrafos. Los márgenes serán de $2,50 \mathrm{~cm}$. En los casos en los que fuera necesario incorporar notas, éstas irán a pie de página, enumeradas consecutivamente, con tipografía Arial 10, interlineado sencillo y justificadas a ambos márgenes.

Una información más detallada se encuentra disponible en la página http://www.um.es/cepoat/ pantarei.

\section{Proceso de valoración y evaluación}

Una vez recibidos los trabajos, la Revista realizará una primera valoración. Si el trabajo enviado se ajusta a las normas de presentación propuestas, la temática es coincidente con la línea editorial de la revista y posee la calidad científica necesaria, será remitido al consejo asesor para una primera evaluación. Si no es así en este primer paso se puede rechazar directamente los documentos que incumplan claramente la línea editorial.

Será el Consejo Asesor quien indique a la revista la originalidad, relevancia, estructura, redacción, aparato bibliográfico, etc. del trabajo enviado y, para ello, se designará a dos revisores expertos externos que evaluarán cada uno de los trabajos, que pueden formar parte (o no) de este Consejo Asesor. La selección de los revisores se ajustará a la temática y características metodológicas del trabajo. El nombre y filiación de los autores serán eliminados del trabajo para su revisión, así como los revisores actuarán de manera anónima y confidencial.

Los revisores deberán rellenar un informe de evaluación que centrará su atención en aspectos tales como características formales, originalidad y novedad de los trabajos, relevancia de las propuestas y los resultados, calidad metodológica y validez científica.

Una vez terminado el proceso se decidirá la aceptación o no de los mismos y su publicación en el número que sea pertinente, así como las modificaciones susceptibles de ser realizadas para su final publicación. Dicha notificación se enviará únicamente por correo electrónico, en un plazo máximo de seis meses. 


\section{Publishing rules}

The author is committed to submit original papers not having been published in other reviews or in other languages. In this way, it is not allowed for the same paper to be presented in other reviews during the evaluation process.

\section{Submission and presentation of originals}

The articles will be exclusively submitted by email to pantarei@um.es. The texts will be submitted in DOC format and the images in JPEG or TIFF format, and with a minimum size of 2000 px. Images will not be integrated in the text but sent in another file and properly numbered according to their position in the text. Attached to the paper, a document will be filled out and sent where the author's data will be specified following the model available on the website.

The sixth edition of the Manual of the American Psychological Association will be taken into account for the writing of the papers. The length of the papers must not exceed 30 pages. Typography will be Arial 11 , with simple line spacing and no space between paragraphs. The text must be justified on both margins without indentation in the first paragraphs. Margins size will be $2.50 \mathrm{~cm}$. Where it could be necessary the incorporation of notes, they will be at the bottom of the page, consecutively numbered with typography Arial 10, simple line spacing and justified on both margins.

More detailed information is available on the website: http://www.um.es/cepoat/pantarei.

\section{Examination and assessment process}

The Journal will submit the papers to a first examination once received. If the paper follows the presentation guidelines, the subject agrees with the editorial line of this journal, and possess the scientific quality required, it will be sent to the advisory council for a first assessment. If not, the documents which clearly fail to complete the editorial line may be rejected straightaway in this first step.

The Advisory Council will indicate the originality, relevance, structure, writing, bibliography, etc. of the text to the journal; for this purpose, two outside experts will be designated to review the papers; these experts can be (or not) part of this Advisory Council. The selection of the experts will adjust to the subject and methodological characteristics of the paper. Name and affiliation of the author will be eliminated from the text for its review, in this way experts will act anonymously and confidentially.

The experts will fill out an assessment report which will focus on aspects such as formal characteristics, originality and novelty of the papers, relevance and results of the proposal, methodological quality and scientific validity.

Once the process is finished, the acceptance or not of the papers and its publication in the corresponding edition will be decided, as well as the modifications that may be done for its final publication. This notification will be sent by email within 6 months maximum. 


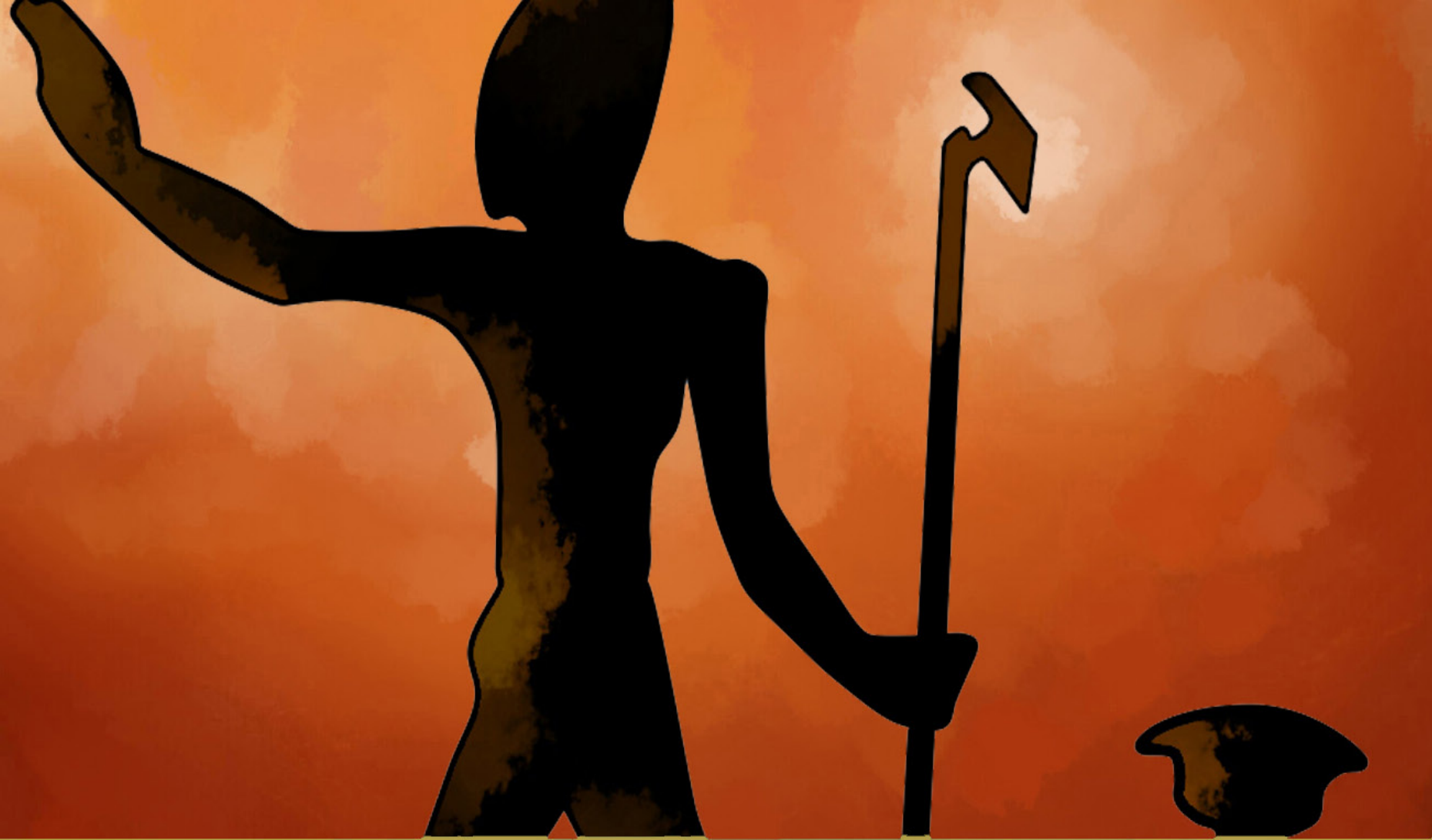

cepo t

UNIVERSIDAD DE MURCIA

centro de estudios del

próximo oriente y la

antigüedad tardía 